\title{
Correction to: A case of fatal acebutolol poisoning: an illustration of the potential of molecular networking
}

\author{
Brendan Le Daré $^{1,2}$ (D) Sophie Allard ${ }^{3} \cdot$ Renaud Bouvet $^{4,5} \cdot$ Alain Baert $^{4} \cdot$ \\ Pierre-Marie Allard ${ }^{6} \cdot$ Isabelle Morel $^{1,3} \cdot$ Thomas Gicquel $^{1,3}$
}

Published online: 24 May 2019

(C) Springer-Verlag GmbH Germany, part of Springer Nature 2019

\section{Correction to: International Journal of Legal Medicine 2019}

https://doi.org/10.1007/s00414-019-02062-9

The published version of this article unfortunately contained a mistake. In Figure 1 on the molecular network of acebutololol, two molecular structures are not displayed ("acebutolol glucuronide "and "impurity J"). The Figure is corrected here.

Publisher's note Springer Nature remains neutral with regard to jurisdictional claims in published maps and institutional affiliations.

The online version of the original article can be found at https://oi.org/ 10.1007/s00414-019-02062-9

\section{Brendan Le Daré}

brendan.ledare@hotmail.fr

1 INSERM, INRA, CHU Rennes, Institut NuMeCan (Nutrition, Metabolism and Cancer), University Rennes, 35000 Rennes, France

2 Pharmacy Service, Rennes University Hospital, 35000 Rennes, France

3 Forensic Toxicology Laboratory, Rennes University Hospital, 35000 Rennes, France

4 Department of Forensic Medicine, Rennes University Hospital, 35000 Rennes, France

5 IDPSP - EA 4640, University Rennes, 35000 Rennes, France

6 School of Pharmaceutical Sciences, University of Geneva and University of Lausanne, Geneva, Switzerland 


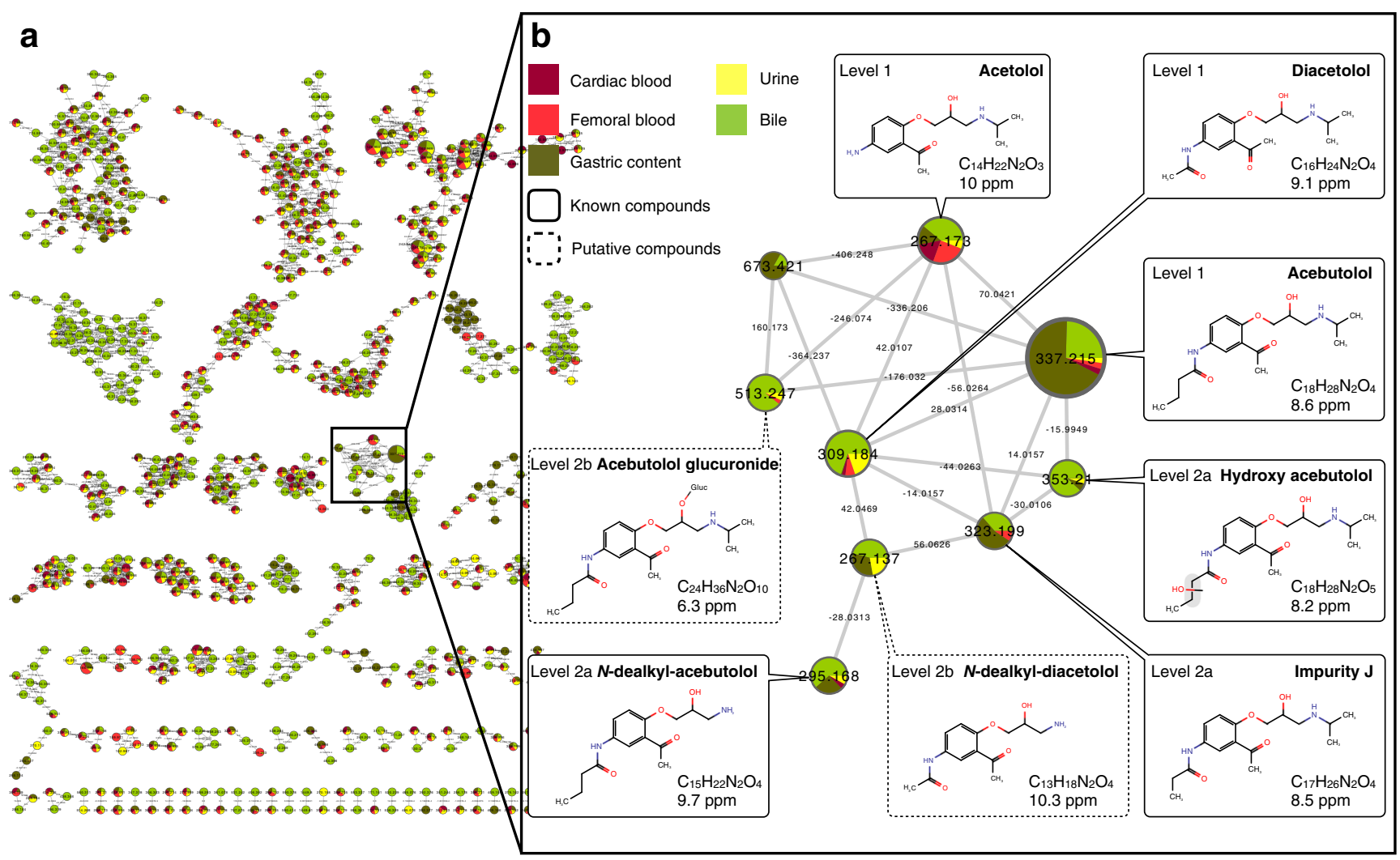

Fig. 1 a The multimatrix molecular network. Each matrix is depicted in a specific color: cardiac blood in dark red, femoral blood in red, gastric contents in khaki, urine in yellow, and bile in green. b Details of the specific acebutolol-containing cluster. Nodes are labelled with the exact protonated mass $(\mathrm{m} / \mathrm{z})$, and chemical structures and the links are labelled with the exact mass shift 